\title{
ANÁLISIS DEL PROCESO DE TRANSICIÓN AL GRADO EN DERECHO: UNIVERSIDAD COMPLUTENSE DE MADRID Y CENTROS ADSCRITOS
}

\author{
Alejandro Rosillo FaiRÉN \\ Doctor en Derecho \\ Profesor de Derecho Civil del CES Cardenal Cisneros \\ arosillo@cu-cisneros.es
}

\section{CONSIDERACIONES GENERALES}

El llamado «Proceso de Bolonia» arrancó en la Facultad de Derecho de la Universidad Complutense de Madrid (UCM) —y, por ende, en los centros adscritos que dependemos de la misma- en el curso académico 2010-2011, justo antes de expirar el plazo impuesto por el RD 1125/2003, de 5 de septiembre, por el que se establece el sistema europeo de créditos y el sistema de calificaciones en las titulaciones universitarias de carácter oficial y validez en todo el territorio nacional.

Esta transformación en los planes de estudios resultó doblemente importante por la singularidad del centro. Así, hasta ese curso se continuaba impartiendo ininterrumpidamente la licenciatura conforme al Plan de $1953^{1}$ — como, por otro lado, continuará haciéndose hasta 2014, sin perjuicio de posteriores convocatorias de examen, ya sin docencia-. Así pues, la Facultad de Derecho UCM asumía Bolonia sin la experiencia previa de la reforma de los títulos superiores iniciada en los años ochenta, que - de manera muy semejante a lo ahora propugnado- tuvo por objeto «acercar la formación universitaria a la realidad social y profesional de nuestro entorno, de suerte que, sin abandonar las irrenunciables tareas de transmitir la ciencia y realizar investigación, pueda la universidad, a través de una oferta coherente de titulaciones académicas, dar respuesta a

${ }^{1}$ Decreto de 11 de agosto de 1953 (BOE, 29 de agosto de 1953, pp. 5187 y 5188). Plan que, por otro lado, no era sino la evolución natural del aprobado en 1900. Por todos, vid. J. HERNANDO MASDEU, «Una perspectiva histórico-comparada de los modelos de planes de estudios de Derecho», en J. Rodríguez-Arana Muñoz y R. Palomino Lozano (dirs.), Enseñar Derecho en el Siglo XXI. Una guía práctica sobre el Grado en Derecho, Navarra, AranzadiThomson Reuters, 2009, p. 55. 
las nuevas demandas del mercado de trabajo» ${ }^{2}$. En esa reforma «intermedia» al alumno le venían impuestas diversas asignaturas (troncales y obligatorias) teniendo la capacidad de elegir entre muchas otras (optativas y de libre configuración) $)^{3}$. Todo ello con una importante aportación en las enseñanzas jurídicas: el practicum.

La impartición del grado en Derecho en la UCM trajo igualmente consigo una nueva medida de la carga de trabajo de los alumnos y del peso de las correspondientes asignaturas. De un sistema clásico —en el sentido más estricto del término-, ajeno por completo a los créditos —uno por cada diez horas de clase-, se pasó directamente a los créditos «nuevos» o ECTS (European Credit Transfer System). Para concluir los estudios de grado es necesario cursar 240 ECTS, a razón de 60 por curso. Y cada ECTS puede considerarse que implica (teóricamente) en torno a treinta horas de trabajo por alumno ${ }^{4}$, efectuándose buena parte del mismo fuera del aula ${ }^{5}$, tal y como indica el art. 3 del antedicho RD 1125/2003:

«El crédito europeo es la unidad de medida del haber académico que representa la cantidad de trabajo del estudiante para cumplir los objetivos del programa de estudios y que se obtiene por la superación de cada una de las materias que integran los planes de estudios de las diversas enseñanzas conducentes a la obtención de títulos universitarios de carácter oficial y validez en todo el territorio nacional. En esta unidad de medida se integran las enseñanzas teóricas y prácticas, así como otras actividades académicas dirigidas, con inclusión de las horas de estudio y de trabajo que el estudian-

2 Exposición de Motivos del Real Decreto 1497/1987, de 27 de noviembre, por el que se establecen directrices generales comunes de los planes de estudio de los títulos universitarios de carácter oficial y validez en todo el territorio nacional.

3 Todo ello conforme al art. 7 del Real Decreto 1497/1987.

${ }^{4}$ Cfr. www.ects.es/es/ects-caracterisiticas.

5 Para muchos docentes eso entraña ciertos riesgos, ya que se está evaluando y computando (con un porcentaje muy relevante en la nota final) un trabajo realizado fuera del aula, desconociéndose a ciencia cierta la autoría real de la correspondiente práctica o si el alumno lo ha realizado enteramente por sí mismo. Evidentemente, esos problemas ya se planteaban con anterioridad, pero indudablemente tenían un carácter menor al computarse tales prácticas de manera usualmente parca en la calificación de la asignatura. A ello ha de unirse el uso masivo de internet, el cual se ha convertido en aliado insustituible (tanto en la perspectiva positiva como en la negativa) del alumnado. Para compensarlo, bien puede implementarse la correspondiente exposición oral de esa práctica — si el número de alumnos así lo permite- y/o realizar otras prácticas de forma individual o colectiva en el aula, contando los estudiantes con los textos de apoyo que consideren oportunos pero bajo la supervisión del docente, de tal forma que el 100 por 100 de la nota de prácticas se distribuya proporcionalmente entre unas y otras, lo cual pudiera resultar más razonable. 
te debe realizar para alcanzar los objetivos formativos propios de cada una de las materias del correspondiente plan de estudios».

Dentro de ese módulo el desarrollo de prácticas pasa a tener una importancia decisiva, colaborando a la formación del estudiante y a prepararle, en mejor medida, a su integración en un mercado laboral cada vez más competitivo. Prácticas que tienen una doble dimensión al desarrollarse dentro de cada asignatura y constituyendo, correlativamente, una asignatura de cuarto curso (practicum). Ahora bien, a día de hoy, restando apenas un año para el comienzo de estas últimas, su próxima aplicación genera considerables (y hasta inquietantes) dudas, acaparando buena parte del documento surgido de la última Conferencia de Decanos de Facultades de Derecho celebrada en Calatayud en abril de 2012 lo que pone de manifiesto la necesidad perentoria de solventar esta cuestión ${ }^{7}$ y la sorprendente inseguridad jurídica que generan determinados aspectos de la reforma.

Evidentemente, tras seis décadas, el cambio introducido en el curso 2010-2011 no resultaba baladí, más aún al prescindirse de esta fase de tran-

${ }^{6}$ Dudas que comprenden aspectos tan trascendentales como la naturaleza, contenido y titulación resultante de las prácticas, su gestión académica, administrativa y económica, así como su convalidación y evaluación. Cfr. www.ucm.es/centros/cont/descargas/documento34272.pdf.

Paradójicamente, los alumnos del futuro máster de acceso a la abogacía deberán cursar igualmente prácticas externas, aunque de forma superior a las realizadas en el cuarto curso de grado. De ahí que al implantarse aquél se plantearán estas mismas dudas, sobre todo en materia de convalidación. Aunque en principio la solución podría ser más simple, ya que las prácticas del grado se desarrollarán necesariamente en el marco de un plan de estudios oficial, con pleno reconocimiento administrativo, la normativa de desarrollo parece escasamente favorable. Así, el Reglamento de reconocimiento y transferencia de créditos en grados y másteres de la Universidad Complutense de Madrid (BOUC, núm. 15, 15 de noviembre de 2010): «Art. 4. Criterios para el reconocimiento de créditos en enseñanzas de máster-1. El reconocimiento de créditos desde la titulación de origen del estudiante se realizará a la enseñanza oficial de máster que se solicite conforme a los siguientes criterios: [...] b) Se podrán reconocer créditos obtenidos en enseñanzas oficiales de Licenciatura, Ingeniería Superior o Arquitectura, enseñanzas todas ellas anteriores al RD 1393/2007, siempre y cuando procedan de asignaturas vinculadas al segundo ciclo de las mismas y atendiendo a la misma adecuación de competencias» (la cursiva es mía).

${ }^{7}$ Dudas que a mi parecer han de extenderse también a la forma en que se van a desarrollar. Por ello, resultaría conveniente tener en cuenta la sugerencia de que se realicen en periodos concentrados, de tal forma que el alumno pueda asistir a diario e integrarse plenamente en la actividad de trabajo ahí realizada. Por todos, vid. J. Gómez Gálligo, «Practicum», en J. Rodríguez-Arana Muñoz y R. Palomino Lozano (dirs.), Enseñar Derecho en el Siglo XXI. Una guía práctica sobre el Grado en Derecho, op. cit., p. 337. 
sición $^{8}$. Durante las seis décadas de vigencia del anterior sistema fueron muchos los que señalaron que aquél se encontraba acertadamente estructurado ${ }^{9}$, aunque con un importante pero: la ausencia de prácticas. O mejor dicho, la ausencia de prácticas institucionalizadas dentro del plan de estudios. Así pues, no era insólito —y no lo será hasta su extinción en 2014que un buen número de docentes realizaran prácticas, pero eso no era sino una actividad a título particular, en función del prudente criterio de cada cual y del desarrollo de la correspondiente libertad de cátedra. Bolonia pretende extender y consolidar esa realidad, conjugando teoría y práctica, marcando igualmente la ponderación de una y otra a través de las «Guías de grado», con las ventajas que ello reporta en cuanto a seguridad jurídica (y probablemente en detrimento de la antedicha libertad). A título particular, como alumno que fui de la Escuela de Práctica Jurídica (EPJ) de la UCM en 2003-2004, creo justo afirmar que —salvando las distancias- podría encontrarse en las EPJ un buen referente de los actuales grados, pues, conforme a las directrices de «evaluación continua», el trabajo por parte de los alumnos era necesariamente constante (los más de cincuenta ejercicios entregados dan fe de ello) y buena parte del mismo se desarrollaba de forma individual fuera del aula, completándose con exposiciones orales ${ }^{10}$.

Paradójicamente, los estudiantes de la licenciatura en Derecho (Plan 1953) reclamaban — reclamábamos_ prácticas al unísono. Ahora, formalizado el cambio, nos encontramos con que la culminación de la tan ansiada meta no es algo gratuito, sino que lleva aparejada consigo una sustancial

${ }^{8}$ De hecho, acaso podría señalarse que la ausencia de estos planes «intermedios» ha resultado negativa, pues en las facultades que sí los asumieron han podido enfocar el grado con un importante bagaje, siendo plenamente conscientes de las dificultades que ya se habían presentado desde la supresión de los antiguos planes y de las medidas que era necesario arbitrar.

9 Esto se puede comprobar en el vigente Plan de Estudios 2009, en el que se mantienen las asignaturas de su predecesor, a lo sumo, matizando contenidos. No obstante, el hecho de que se aumente el número de materias cursadas, añadiendo las correspondientes prácticas, y que todo ello deba verificarse en un año menos (cuatro cursos frente a los cinco del Plan 1953) hacen que el cambio sea de fortísimo calado. Más aún cuando los alumnos de primer curso de grado deben enfrentarse a asignaturas en su día explicadas en tercero de licenciatura, con una madurez y experiencia personal muy diferentes al empezar una y otra, de ahí que eso redunde en una mayor dificultad, siendo la incorporación a la universidad bastante abrupta para buena parte de los alumnos del grado.

${ }^{10}$ Otro punto de interés es la mayor motivación de los alumnos que realizan este tipo de cursos, tanto por contar con una mayor madurez, derivada de la edad, como por tener un coste muy superior al de las tasas oficiales de las universidades públicas. Ello en sí mismo resulta un elemento altamente incentivador, sobre todo en los casos en que el alumno asume la responsabilidad de sufragar los mismos, bien en su totalidad o en parte. 
alteración de la manera de proceder el estudiante que - como sus antecesores en los cursos de postgrado- imperativamente ha de desarrollar un trabajo continuado a lo largo del curso. Así cabe recordar en este punto el art. 8.d) del Real Decreto 1791/2010, de 30 de diciembre, por el que se aprueba el Estatuto del Estudiante Universitario, titulado «Derechos específicos de los estudiantes de grado», el cual señala que los estudiantes de grado tienen dentro de sus derechos específicos «recibir una formación teórico-práctica de calidad y acorde con las competencias adquiridas según lo establecido en las enseñanzas previas». Y para llevar a la práctica este derecho se implementa el correspondiente deber en la misma norma: «Art. 13. Deberes de los estudiantes universitarios.-1. Los estudiantes universitarios deben asumir el compromiso de tener una presencia activa y corresponsable en la universidad, deben conocer su universidad, respetar sus Estatutos y demás normas de funcionamiento aprobadas por los procedimientos reglamentarios. 2. Entendidos como expresión de ese compromiso, los deberes de los estudiantes universitarios serán los siguientes: a) el estudio y la participación activa en las actividades académicas que ayuden a completar su formación».

Sea como fuere, se ha afirmado en muchas ocasiones que esta transformación también supone un cambio radical para los docentes, propiciando una modificación absoluta en el modelo de enseñanza ${ }^{11}$, lo cual es tan cierto $^{12}$ como incompleto ${ }^{13}$, pues este panorama general es contemplado de forma bastante crítica por buena parte de los alumnos, lo que justificaré en apartados posteriores. Sobremanera cuando sus inmediatos predece-

${ }^{11}$ «El rol del maestro no es enseñar (en el sentido de presentar los temas de las asignaturas), sino conducir el medio instruccional, diagnosticar alumnos, dirigir el uso de los recursos disponibles, coordinar información, etc.». Cfr. C. CHADwick, Tecnología educacional para el docente, Buenos Aires, Paidós-Biblioteca del Educador Contemporáneo, 1975, p. 183.

12 Valgan como muestra los Principios y orientaciones 2.0 del Programa Academia, aprobados en enero de 2012: «Como consecuencia, el Pleno del Consejo de Universidades celebrado el 3 de noviembre de 2011 aprobó la revisión del documento Principios y Orientaciones para la Acreditación del Profesorado que ofrece directrices tanto a las propias comisiones de acreditación como a los profesores que opten a la acreditación para los niveles de profesor titular de universidad o catedrático de universidad. El documento parte de un principio fundamental que es proveer al sistema universitario de un profesor moderno y adaptado a las nuevas exigencias de la universidad, principalmente la adaptación al Espacio Europeo de Educación Superior, así como la contribución universitaria al modelo económico basado en el conocimiento y la transferencia. Define con claridad a un profesor integral cuyas tareas docentes, investigadoras y de transferencia e innovación son consustanciales a su misión» (la cursiva es mía).

${ }^{13}$ Más adelante comentaré algunos de los condicionantes de este proceso. 
sores en la universidad gozaron de una mucha mayor libertad durante el curso, pues dicho trabajo continuado - aunque conveniente- era escasamente practicado al no ser consustancial a buena parte de las licenciaturas. Téngase en cuenta que los actuales protagonistas en no pocas ocasiones se muestran reticentes a asumir las nuevas cargas que trae aparejada el sistema. No en vano, Bolonia pretende desarrollar «una docencia centrada en el estudiante, lo que requiere capacitarlo para el aprendizaje autónomo y dotarlo de herramientas para el estudio» ${ }^{14}$, de tal forma que el discente sea capaz de «aprender a aprender» ${ }^{15}$.

$\mathrm{La}$ tradicional clase magistral pierde protagonismo al configurarse «como una herramienta más de una nueva metodología educativa que debe incorporar una forma de aprendizaje más autónoma, reflexiva, multidisciplinar y práctica» ${ }^{16}$. Evidentemente, tal cambio implica no sólo más trabajo para el estudiante, sino una mucho mayor responsabilidad, disciplina y organización desde el comienzo del curso. La madurez del alumno deviene pieza básica del EEES.

Las guías de las asignaturas, instrumentos vinculantes para todos los agentes en este proceso, son el cauce que nos introduce al trascendental cambio ${ }^{17}$ :

«El alumno deberá haber realizado una lectura previa de los temas que se desarrollarán en estas clases, asumiendo que la comprensión de los mismos no queda confiada exclusivamente a la labor del docente (y, en su caso, con el fin de acreditar, mediante las intervenciones que pudieran ser requeridas, el trabajo realizado individualmente)».

Se consolida imperativamente (al menos en el marco teórico) una nueva forma de trabajar que antaño era practicada por una absoluta minoría: «Con el nuevo planteamiento del método expositivo es razonable pensar que el alumno deberá seguir tomando notas en clase al viejo uso, pero

${ }^{14}$ Cfr. M. A. Zabalza Beraza, Guía para la planificación didáctica de la docencia universitaria en el marco del EEES. Guía de guías. Documento de trabajo, disponible en www.unavarra.es/conocer/calidad/pdf/guiaplan.PDF, p. 3.

${ }_{15}$ Por todos, vid. R. Palomino Lozano, «Introducción. Las claves del EEES: principios, reglas y recomendaciones», en J. Rodríguez-Arana Muñoz y R. Palomino Lozano (dirs.), Enseñar Derecho en el Siglo XXI. Una guía práctica sobre el Grado en Derecho, op. cit., p. 32.

${ }^{16}$ Cfr. www.educacion.gob.es/boloniaensecundaria/glosario-c.htm.

${ }_{17}$ Guía de Derecho Civil III para el curso 2011-2012 en la UCM, disponible en www.ucm.es/info/derecho/web/wp-content/themes/derecho/pdfs/GradoDerecho/segundo/ civil_3_2.pdf 
lo aconsejable será que acuda a ella pleno de información y con la finalidad de poder participar con intensidad en los diálogos y debates que se susciten con el profesor y con sus compañeros sobre cuestiones de las que previamente habrá debido informarse y sobre las que habrá tenido que reflexionar» ${ }^{18}$. Esto es, junto a la lectura previa de los temas a explicar devendría necesaria la asimilación de los mismos.

De ahí que, tal y como acertadamente se señala en la página web del grado en Derecho de la UCM en las recomendaciones de acceso: «El perfil más adecuado es el del estudiante con grandes deseos de aprender y de esforzarse por conseguirlo; con habilidades comunicativas (orales y escritas); reflexivo y crítico; especialmente interesado en las ciencias sociales y jurídicas» ${ }^{19}$. Así pues, el requisito básico sería comenzar el grado asumiendo como propias tales exigencias, a lo que habrían de unirse importantes dosis de disciplina, organización y adecuada motivación. Y a diferencia de lo que ocurría en épocas anteriores, esta última es una de las tareas en la que, de forma continuada, habrá de trabajar este nuevo profesor. No en vano se ha señalado certeramente que ninguna meta puede alcanzarse «a menos que se influya sobre el estudiante para que se torne en cierto modo diferente de lo que era antes de la enseñanza» ${ }^{20}$.

Ahora bien, el problema — de considerable entidad — surge cuando se quiebran tales presupuestos y el alumno accedió a los estudios sin atender al perfil sugerido, decide no atender las indicaciones de la Guía de grado (por ejemplo, matriculándose de una asignatura sin cumplir los conocimientos previos recomendados) o la labor motivadora resulta insuficiente. Surgirá entonces la disyuntiva en el docente de replantear - $\mathrm{O}$ no- la forma en que desarrollará Bolonia.

\section{CONDICIONANTES DEL PROCESO DE BOLONIA}

Antes de incluir y valorar los resultados de las encuestas cumplimentadas por los alumnos entiendo necesario realizar diversas observaciones.

${ }^{18}$ Cfr. C. Llorente Gómez de Segura, «La lección expositiva en las materias jurídicas», en J. Rodríguez-Arana Muñoz y R. Palomino Lozano (dirs.), Enseñar Derecho en el Siglo XXI. Una guía práctica sobre el Grado en Derecho,op. cit., p. 137.

${ }_{19} \mathrm{Cfr}$. www.ucm.es/info/derecho/web/nuevas-titulaciones/grados/grado-en-derecho/ todo-sobre-grado-en-derecholacceso-y-perfil-de-ingreso.

${ }^{20}$ Cfr. R. MAger, Actitudes positivas en la enseñanza, México DF, Pax-México, Librería Carlos Cesarman, 1971, p. 22. 
El Centro de Estudios Superiores Cardenal Cisneros es una institución de gestión privada que cuenta a día de hoy con 1.000 alumnos distribuidos en las siguientes titulaciones: Psicología, Derecho, ADE y Derecho+ADE. Las clases, como regla general, tienen un reducido tamaño - a excepción de las destinadas a conferencias u otras actividades de carácter análogo- lo que permite un trato próximo y cercano entre el docente y el alumno, esto es, una adecuada interacción. Ese ventajoso contexto favorecía desde su creación, en 1971, la realización de prácticas en las licenciaturas (tanto «clásicas» como «renovadas»), suponiendo igualmente un satisfactorio punto de partida la correcta aplicación del sistema Bolonia, lo que a priori podría traslucirse en una mejor valoración del mismo por los estudiantes.

Por otro lado, en diversos centros públicos, el problema básico reside - como antaño- en el elevado número de alumnos, unido al aumento de carga lectiva de los docentes. La tan afamada frase «Bolonia coste cero» ${ }^{21}$ se ha convertido en indiscutible realidad, pese a ser altamente cuestionada por diversas autoridades ${ }^{22}$, sobre todo tras la paulatina reducción del profesorado ${ }^{23}$. Sin embargo, al menos de forma tácita, los documentos oficiales apuntan - como no podía ser menos- a un aumento de los costes educativos para la correcta implantación del sistema. Así, el Comunicado de Lovaina/Lovaina la Nueva de 28-29 de abril de 2009, «El Proceso

${ }^{21}$ Paradójicamente, ello guarda estricta coincidencia con lo ocurrido dos décadas atrás en la anterior reforma de los planes de estudios. Sobre esta cuestión, por todos, vid. J. InFANTE DíAz, «La reforma de los planes de estudio universitarios de la España democrática (1977-2000)», Revista de Educación, núm. 351 (2010), pp. 272 y ss.

22 «Ominosa pretensión», según Canosa Usera, «Prólogo», en J. Rodríguez-Arana Muñoz y R. Palomino Lozano (dirs.), Enseñar Derecho en el Siglo XXI. Una guía práctica sobre el Grado en Derecho, op cit., p. 21.

23 Así, el Real Decreto-ley 20/2011, de 30 de diciembre, de medidas urgentes en materia presupuestaria, tributaria y financiera para la corrección del déficit público: «Art. 3. Oferta de empleo público u otro instrumento similar de gestión de la provisión de necesidades de personal.-Uno. A lo largo del ejercicio 2012 no se procederá a la incorporación de nuevo personal, salvo la que pueda derivarse de la ejecución de procesos selectivos correspondientes a Ofertas de Empleo Público de ejercicios anteriores o de plazas de militares de tropa y marinería necesarios para alcanzar los efectivos fijados en la disposición adicional décima de la Ley 39/2010, de 22 de diciembre, de Presupuestos Generales del Estado para el año 2011. Esta limitación alcanza a las plazas incursas en los procesos de consolidación de empleo previstos en la disposición transitoria cuarta del Estatuto Básico del Empleado Público. Dos. Durante el año 2012 no se procederá a la contratación de personal temporal ni al nombramiento de personal estatutario temporal o de funcionarios interinos salvo en casos excepcionales y para cubrir necesidades urgentes e inaplazables que se restringirán a los sectores, funciones y categorías profesionales que se consideren prioritarios o que afecten al funcionamiento de los servicios públicos esenciales». 
de Bolonia 2020. El Espacio Europeo de Enseñanza Superior en la nueva década», en el cual se pone de manifiesto que «deben encontrarse fuentes de financiación nuevas y más diversas que complementen la financiación pública». Evidentemente, algunos ejemplos existen de ello, pero a día de hoy no suponen en modo alguno la regla general ${ }^{24}$. De ahí que, más certeramente, habría que señalarse que Bolonia ha traído aparejada una sorprendente reducción de costes, algo impensable al fraguarse su creación. Todo ello mientras se propone el aumento de los ingresos, cuya primera consecuencia ha sido la subida del precio de las matrículas, sobremanera a los alumnos repetidores.

A modo de ejemplo, pensemos en una aplicación estricta —o que no lo sea tanto- del «Sistema Bolonia» con una cifra de 300 alumnos distribuidos en varios grupos (situación que se encuentra dentro de la más estricta normalidad para los profesores de la enseñanza superior pública a tiempo completo y aun para muchos otros a tiempo parcial — por ejemplo, Titulares 6+6-). Ello per se resulta una tarea verdaderamente titánica, ya que - a mi juicio- ello se sitúa manifiestamente en contra de los compromisos asumidos por los Estados, tales como «la calidad» 250 «el fomento de medidas encaminadas a hacer más atractivo el EEES entre los estudiantes tanto europeos como de otras partes del mundo» ${ }^{26}$. Pero no puede olvidarse que España cuenta con una elevada cifra de universitarios, en torno a 1.650.000 durante el curso 2011-2012, cursando la mayor parte de ellos sus estudios en centros de titularidad pública que, evidentemente, participan del adverso contexto económico y de la merma de recursos disponibles.

No estamos hablando aquí de un ligero aumento de la ratio de alumnos por clase, como el planteado en otros niveles educativos, sino que el número de alumnos por clase en la enseñanza superior — con tenden-

${ }^{24}$ Así, la Cátedra de Distribución Comercial de la Fundación Ramón Areces-Universidad de Oviedo, que desarrolla su actividad en tres ámbitos de actuación: investigación científica, formación de capital humano y difusión del conocimiento (cfr. www.fundacionareces. es/fundacionareces/portal.do? IDM=74ENM=1). Por otro lado, cabe destacar así lo señalado por el rector de la UCM, profesor Carrillo Menéndez, en su reciente comparecencia ante la Asamblea de la Comunidad: «Entre las medidas de generación de mayores ingresos estables podemos citar [...] la puesta en marcha de un sistema de fundraising de captación de fondos, a imagen de lo que hacen otras universidades conocidas en el mundo en torno a este tema» (cfr. Diario de Sesiones de la Asamblea de Madrid, núm. 197, 23 de mayo de 2012, IX Legislatura, 10141).

${ }^{25}$ Se ha señalado que podrían trabajar hasta cincuenta alumnos en grupo siempre y cuando el local reúna los requisitos necesarios. Cfr. A. Brockbank y I. McGill, Aprendizaje reflexivo en la educación superior, Madrid, Morata, 2002, p. 189.

${ }^{26}$ Comunicado de Praga de 19 de mayo de 2001. 
cia a aumentar durante los próximos años- resulta difícilmente compatible con las «piedras angulares» del sistema ${ }^{27}$. Efectivamente, no deberían obviarse los objetivos sobre los que se asentó «Bolonia», reformulando en su caso los aspectos que sean necesarios ${ }^{28}$. Téngase en cuenta igualmente que doctrinalmente se ha señalado que «lo esencial es constatar que la unidad fundamental del proceso de construcción del conocimiento se concreta en la interactividad. Ello la identifica, a su vez, como la unidad clave del análisis de la calidad de los procesos de enseñanza y de aprendizaje dirigidos a apropiarse de contenidos de aprendizaje determinados ${ }^{29}$.

Con independencia de lo anterior, la aplicación stricto sensu del nuevo sistema con tales condicionantes lleva a consecuencias verdaderamente chocantes. Impartir «clases magistrales» de forma interactiva con un número tan elevado de alumnos no resulta tarea sencilla. Doctrinalmente se ha señalado que «la suposición fundamental del modelo clásico es que, dados los recursos y el tiempo necesarios, una persona puede enseñar adecuadamente un conjunto de información más o menos clara y preestablecida a un pequeño número de alumnos» ${ }^{30}$. Pero bajo mi criterio, el elevado volumen de discentes también condiciona la ejecución del nuevo sistema.

No obstante lo anterior, se suscitan mucho mayores dificultades con las prácticas. En primer lugar, por los condicionantes físicos. Bolonia requiere —al menos teóricamente- bibliotecas de mayor tamaño que las anteriores y ampliamente surtidas de los libros de consulta de referencia en cada asignatura. Igualmente, un mayor número de licencias para la utilización de las bases de datos jurídicas en el grado en Derecho, más ordenadores, internet, wifi, etc. A eso hay que añadir el tamaño y la distribución de las aulas y, en menor medida, la distancia al profesor de muchos alumnos o la acústica. Y aun considerando que tales elementos tienen un carácter menor, queda aún una dificultad prácticamente insalvable: el

${ }^{27}$ En los grupos estudiados por Rodríguez Rivas y Cosculluela Martínez, pertenecientes a la Universidad Rey Juan Carlos, el 20 por 100 demandó expresamente una enseñanza de carácter más personalizado con menos alumnos por clase. Cfr. A. RodRíguez Rivas y C. CosCULLUELA MARTíNEZ, «Los estudiantes demandan más carga docente en asignaturas clave para su formación profesional», Actas de las III Jornadas en Innovación y TIC Educativas (JITICE 2012), Boletín de la Escuela Técnica Superior de Ingeniería Informática, Universidad Rey Juan Carlos, núm. 2012-001, p. 31.

${ }^{28}$ Cfr. A. Rodríguez Rivas y C. Cosculluela Martínez, «Los estudiantes demandan más carga docente en asignaturas clave para su formación profesional», op. cit., p. 29.

${ }^{29}$ Cfr. T. Mauri, J. Onrubia, C. Coll y R. Colomina, «La calidad de los contenidos educativos reutilizables: diseño, usabilidad y prácticas de uso», Revista de Educación a Distancia, p. 4, disponible en www.revistas.um.es/red/article/view/25091/24371.

${ }^{30}$ Cfr. C. Chadwick, Tecnología educacional para el docente, op. cit., p. 48. 
tiempo. Conforme a los designios de Bolonia, muchos docentes entienden que lo más pedagógico — a la par que ético— sería corregir todas las prácticas. No obstante, dedicar apenas tres minutos a la corrección de cada ejercicio (siguiendo con el supuesto anterior, un profesor con 300 alumnos divididos en varios grupos) supondría invertir la friolera de quince horas, esto es, el 40 por 100 del tiempo lectivo semanal de unos profesionales que por definición han de tener un perfil docente e investigador [así los arts. 51.b), 52.b) y 56.1 de la Ley Orgánica 6/2001, de 21 de diciembre, de Universidades].

Así pues, tales condicionantes marcan el devenir del curso y, en el mejor de los casos —o en el más probable—, la corrección forzosamente pasará a tener un carácter general, ya que no es posible dedicar al alumno el tiempo necesario para realizar una corrección individual y darle posteriormente al interesado - como así sería deseable — una explicación particular de los fallos que ha podido cometer ${ }^{31}$. Evidentemente, no habría problemas en aplicar otras posibilidades, como la exposición oral de prácticas o trabajos, preferentemente por grupos, para permitir que todos los alumnos puedan intervenir y ser valorados por su intervención, al menos una vez por asignatura.

La preconizada interacción evidentemente podrá aplicarse en cierta medida —incluso en docentes desconocedores de la misma- ${ }^{32}$, pero no en la ambiciosa forma prevista por Bolonia, por cuestiones que exceden $-\mathrm{y}$ con mucho- a las competencias del profesorado. Y hace que el nuevo sistema sea cuestionado por los alumnos, con el riesgo de que una valoración negativa del plan de estudios pueda igualmente repercutir en el profesorado a través de las correspondientes encuestas docentes, elemento básico - y obligatorio- para que el alumno pueda pronunciarse sobre el proceso formativo.

${ }^{31}$ Una solución intermedia sería que los alumnos que tuvieran un especial interés demandaran esas explicaciones complementarias en las tutorías, las cuales se encuentran infrautilizadas a día de hoy. Hecho este que tiene justificación, al menos parcial, ya que el horario de tutorías se desarrolla mientras el alumno acude a otras clases, las cuales en principio tienen un carácter obligatorio. Problema que resulta de compleja solución.

32 «Hay docentes que no son conscientes del procedimiento o de la relación potencial entre la enseñanza y el aprendizaje ni de los requisitos de un aprendizaje que pueda ser reflexivo. El hecho de que el profesor sea inconsciente del procedimiento no significa que no utilice técnicas ni destrezas en su interacción con los alumnos. Es posible que el docente no tenga conciencia del procedimiento o sólo la tenga en parte, pero, a la fuerza, en su ejercicio de enseñante tendrá que desarrollar alguna forma de interacción que utilice técnicas y destrezas» (A. BRockBANK y I. McGiLl, Aprendizaje reflexivo en la educación superior, op. cit., p. 111).

Foro, Nueva época, vol. 15, núm. 2 (2012): 309-336 
En las últimas décadas, como es bien conocido, se han sucedido diversas leyes de educación en España. Tal exceso normativo, sin embargo, no ha logrado invertir un hecho que parece palmario: la menor calidad de la misma, que lejos de ser una impresión más o menos subjetiva de la sociedad, se confirma desde diversas instancias internacionales. Así, el Informe PISA. La realidad entra en flagrante contradicción con lo dispuesto en la vigente Ley Orgánica 2/2006, de 3 de mayo, de Educación, que proclama la calidad como primer principio del sistema educativo español [art. 1.a)]. Para alcanzar la misma se consolidan los correspondientes Principios generales, que en la última fase de la enseñanza preuniversitaria son los siguientes: «Art. 32.1. El bachillerato tiene como finalidad proporcionar a los alumnos formación, madurez intelectual y humana, conocimientos y habilidades que les permitan desarrollar funciones sociales e incorporarse a la vida activa con responsabilidad y competencia. Asimismo, capacitará a los alumnos para acceder a la educación superior».

E igualmente se indican los Objetivos de la citada etapa: «Art. 33. El bachillerato contribuirá a desarrollar en los alumnos y las alumnas las capacidades que les permitan: [...] b) Consolidar una madurez personal y social que les permita actuar de forma responsable y autónoma y desarrollar su espíritu crítico. Prever y resolver pacíficamente los conflictos personales, familiares y sociales [...] d) Afianzar los hábitos de lectura, estudio y disciplina, como condiciones necesarias para el eficaz aprovechamiento del aprendizaje, y como medio de desarrollo personal [...] k) Afianzar el espíritu emprendedor con actitudes de creatividad, flexibilidad, iniciativa, trabajo en equipo, confianza en uno mismo y sentido crítico».

Muy probablemente, si tales objetivos se cumplieran, la implantación de Bolonia podría haberse realizado, desde el primer momento, con muchas mayores garantías. Sin embargo, alcanzar tales objetivos en dos años de bachillerato $^{33}$, cuando las generaciones inmediatamente anteriores tuvieron cuatro cursos de enseñanza media no obligatoria, parece una tarea compleja. Guste o no, el profesor de universidad en muchas ocasiones habrá

33 Según la Exposición de Motivos del Anteproyecto de Ley Orgánica para la mejora de la calidad educativa, objeto de un intenso debate público en los albores de 2013: «La objetividad de los estudios comparativos internacionales, que reflejan como mínimo el estancamiento del sistema, llevan a la conclusión de que es necesaria una reforma del sistema educativo que huya de los debates ideológicos que han dificultado el avance en los últimos años. Es necesaria una reforma sensata, práctica, que permita desarrollar al máximo el potencial de cada alumno». Sin embargo, la duración del bachillerato queda fuera de la reforma planteada. 
de trabajar sobre los antedichos objetivos generales, presupuesto necesario para tratar de alcanzar las competencias previstas en el grado.

Por otro lado, la utilización del campus virtual y del correo electrónico permite una mayor agilidad y redunda en beneficio de profesores y alumnos, ya que la comunicación es ágil y fluida. Se faculta a través de estas herramientas la puesta a disposición de los alumnos de los materiales y prácticas, enlaces de interés (Congreso de los Diputados, Senado, Boletín Oficial del Estado, Ministerio de Justicia) y un largo etcétera. Se ha señalado que estos medios tecnológicos «liberan al profesor de su histórico papel de presentar contenidos permitiéndole preocuparse por funciones más valiosas y complejas, tales como el diagnóstico, la creación de diversas experiencias de aprendizaje, el estímulo de motivación de potenciales individuales, la participación, el control y la coordinación de grupos de conducta (debates, discusiones, etcétera)» ${ }^{34}$.

Sin embargo, a mi juicio, se corre aquí el riesgo de morir de éxito. En una enseñanza on-line es perfectamente entendible que los alumnos utilicen preferentemente esta vía de comunicación, ya que es el medio básico que se les da para contactar con el docente. En ese contexto, que cada alumno envíe un correo por módulo se encuentra dentro de la más absoluta normalidad. Lo que implica que un grupo de 100 alumnos en una asignatura de catorce módulos (a razón de uno por semana) enviará en torno a 1.400 correos electrónicos en un cuatrimestre. En una enseñanza presencial, la utilización del correo electrónico de esa misma forma supondría un notorio sobreesfuerzo para el docente ${ }^{35}$. Para optimizar recursos existe el uso extendido entre muchos profesores de responder de forma general a todos los alumnos cuando dos o más estudiantes formulan preguntas en el mismo sentido, hecho éste que, como regla general, es bien recibido entre el alumnado. Práctica que acaso puede alentar a un mayor seguimiento y esfuerzo en el curso ${ }^{36}$. Pero el problema surge cuando el alumno pretende - lo que no es infrecuente- sustituir la tutoría presencial por la tuto-

34 Cfr. C. Chadwick, Tecnología educacional para el docente, op. cit., p. 78.

${ }_{35} \mathrm{Mi}$ experiencia personal durante el curso 2011-2012 ha sido bastante razonable al recibir en torno a 300 correos electrónicos de alumnos durante el curso, cifra que al parecer resulta muy inferior a la de otros docentes de diferentes universidades. El consignar puntualmente en el campus virtual la información básica del curso, sistemas de evaluación, fechas de exámenes, publicación de notas y revisiones, ha provocado - a mi juicio- que el número de correos no haya sido exagerado.

${ }^{36}$ Cfr. R. Palomino Lozano, «El uso de las TIC's en la enseñanza y aprendizaje de los estudios jurídicos», en J. Rodríguez-Arana Muñoz y R. Palomino Lozano (dirs.), Enseñar Derecho en el Siglo XXI. Una guía práctica sobre el Grado en Derecho, op. cit., p. 313. 
ría on line, pretendiendo que ésta discurra de la misma forma que aquélla, esto es, con la misma extensión. No puede olvidarse que el papel de estas TIC's, aunque valioso, no deja de ser meramente auxiliar ${ }^{37}$.

A lo anteriormente expuesto se unen otros problemas que eran desconocidos con los antiguos planes de estudios. Especialmente relevante es el hecho de que en el «día de prácticas» — como ha pasado a conocerse en la jerga universitaria - sean muchos los profesores que por la configuración de los horarios (por ejemplo, dos grupos de ocho ECTS en un mismo cuatrimestre) en no pocos casos deban impartirse nada menos que seis horas de clase consecutivas, con el consiguiente sobreesfuerzo y la correlativa merma de calidad. En ese marco, objetivos tales como la motivación o la interacción con los alumnos han de postergarse. Esta circunstancia - de compleja solución por la ausencia de recursos suficientes- está siendo obviada por el momento.

Otra cuestión que tampoco puede obviarse, a mi juicio, es que, a diferencia de los centros públicos en los que existe una «nota de corte», en los privados el alumno que accede a los mismos ingresa directamente en los estudios deseados (pues si no existe tal posibilidad, normalmente no ingresará en el mismo). Esa nota de corte, creciente en determinadas carreras, provoca que en no pocos casos no se realice la carrera deseada o que no se curse en la universidad elegida en primera instancia, lo que puede generar un contexto más crítico entre estos últimos alumnos, a priori menos motivados al ser sabedores de que no podrán alcanzar su objetivo primario, pudiendo resultar algo más compleja la implantación de Bolonia en este sector.

Así pues, todos estos aspectos han de ser ponderados en su justa medida. Obviarlos sería manifiestamente injusto, ya que en ciertas ocasiones el descontento de los alumnos al no verse colmadas sus expectativas se va a plasmar a través del principal elemento que aquéllos tienen a su disposición: las encuestas docentes. Evidentemente, utilizarlas para esta finalidad de protesta contra el sistema -o contra el docente que aplica el mismo según su más leal saber y entender- ni es lo deseable ni probablemente va a suceder así de forma general, pero es un elemento que debe tenerse en cuenta, sobre todo a la hora de ponderar sus resultados.

${ }^{37}$ Ibid., p. 314. 


\section{ENCUESTAS REALIZADAS: JUSTIFICACIÓN Y TOMA DE DATOS. CUESTIONARIO PROPUESTO AL ALUMNADO}

Teniendo en cuenta lo ya expuesto, ante un cambio de semejante calado este autor entiende imprescindible el analizar, cuestionar y desarrollar la implantación del grado en Derecho. Todo ello con el ánimo de comprobar tanto la adecuación de los alumnos a la dinámica impuesta por Bolonia como para verificar la opinión real de aquéllos sobre el nuevo marco docente. Más aún si se tienen en cuenta las objeciones que los alumnos habían planteado verbalmente y de forma general — no a nivel de una u otra disciplina - en relación con la implantación del grado a lo largo del curso, por las exigencias y el trabajo continuado que lleva aparejado consigo. A mi juicio, simplemente por esa razón, con independencia del plan de estudios empleado, quedaría suficientemente justificado un trabajo de esta naturaleza.

Otro de los objetivos básicos será — tras analizar los resultados- el tratar de mejorar aquellos aspectos que resulten susceptibles de cambio, introduciendo las alteraciones que sean pertinentes en los próximos años aprovechando la flexibilidad de Bolonia, permitiendo así un mejor encaje entre las exigencias de las Guías de grado y las demandas de los alumnos.

Eso permitirá al autor, en cursos venideros, continuar el análisis, tanto con los grupos de referencia aquí analizados como con los nuevos que se incorporen, para comprobar si las rectificaciones aconsejadas por la práctica han sido útiles en el proceso de formación del alumnado y si han sido recibidas correctamente por los mismos.

Para ello se ha utilizado un mecanismo impulsado en este periodo de transición: las encuestas a los alumnos. A mi juicio, Bolonia se encuentra aún en fase de construcción (o mejor dicho, es un proceso destinado a construirse permanentemente) y por ello, lejos de ser instrumentos carentes de utilidad, a través de las encuestas se puede perseguir un objetivo tan loable como la mejora continua de la enseñanza, basada en hechos y medidas concretas que pueden partir de los alumnos. Ninguna utilidad tendría implantar el EEES de espaldas a los discentes, y, de hecho, sus sugerencias pueden ser decisivas.

La toma de datos se produjo durante el mes de mayo de 2012 en el CES Cardenal Cisneros, entre los alumnos de primer curso del grado en Derecho, grupos de mañana y tarde $\left(1 .^{\circ} \mathrm{A}\right.$ y $\left.1 .^{\circ} \mathrm{E}\right)$, con antelación suficien- 
te a la realización de los exámenes finales para evitar posibles distorsiones. Al tratarse de alumnos de primer curso, por aplicación de la normativa todos los discentes se encontraban matriculados en la totalidad de las nueve asignaturas que componen el curso $^{38}$. En concreto, las encuestas se realizaron en el horario de clase de la materia «Derecho Civil II».

Las encuestas se realizaron sin preaviso alguno — siguiendo idéntica fórmula que los cuestionarios sobre evaluación docente ahí realizados- - y de forma voluntaria entre los alumnos que quisieron participar, que finalmente resultaron ser el 100 por 100. En todos los cuestionarios repartidos los alumnos respondieron a la totalidad de las preguntas, con excepción de la quinta y última, lo que se justifica por su carácter «abierto», tal y como se desarrollará en el apartado siguiente de este trabajo.

Tras proponerles dicha actividad, únicamente se pidió a los interesados que indicaran en los formularios si pertenecían al turno de mañana o al de tarde, al objeto de poder realizar a posteriori una comparativa entre los datos, solicitándoles expresamente que no consignaran su nombre.

De forma complementaria se realizaron las mismas encuestas - bajo idénticas condiciones - en un grupo de tercero de licenciatura (Plan 1953) cuyos alumnos cursaban la materia «Derecho Civil II» ${ }^{39}$. A estos últimos -lógicamente- se les pidió que todas las referencias existentes en el cuestionario sobre el «grado» fueran sustituidas por «licenciatura». Las razones que justifican ampliar el estudio a alumnos de planes no renovados son varias. En primer término, la existencia de una identidad de razón entre el contenido de una y otra asignatura, así como en la forma de impartir y calificar la misma. En ambos casos, existió el mismo empleo de tutorías, materiales dispuestos en el campus virtual, configuración de exámenes (parcial y final), etc. Tales datos permitirán saber si en grupos en los cuales no se había empleado Bolonia con anterioridad, tal experiencia resulta satisfactoria o negativa y las razones que pueden justificar dicha circunstancia.

Por razones operativas se decidió utilizar un cuestionario ya utilizado con anterioridad por Rodríguez Rivas y Cosculluela Martínez ${ }^{40}$ en la uni-

38 Así, Historia del Derecho, Teoría del Derecho, Derecho Romano: historia e instituciones, Derecho Constitucional I y Derecho Civil I, en el primer cuatrimestre, y Derecho Eclesiástico, Introducción a la Economía, Derecho Constitucional II y Derecho Civil II, en el segundo.

39 Junto a Derecho Penal II, Derecho Administrativo I, Derecho Internacional Público y Hacienda Pública.

${ }^{40}$ Cfr. «Los estudiantes demandan más carga docente en asignaturas clave para su formación profesional», op. cit., pp. 29 y ss. 
versidad Rey Juan Carlos de Madrid. Los motivos que justifican esta elección son múltiples. De una parte, destacar su novedad y la difusión de sus resultados en el marco de unas jornadas con considerable participación. De otra, más relevante aún —a juicio de este autor-, son lo acertadas que resultan las preguntas formuladas (al centrarse en las cuestiones clave de la implantación de Bolonia, con independencia de la rama de conocimiento a la que se adscriba cada carrera), así como también la coincidencia existente en cuanto a criterios, objetivos y metodologías empleadas en función de lo manifestado por las antedichas profesoras. $Y$ otra de las ventajas de haber optado por tal trabajo es el hecho de que no sólo se haya puesto en práctica, sino de la forma en que se ha verificado, con considerable amplitud de la muestra, de la cual pueden extraerse conclusiones con mayor grado de fiabilidad.

Dicho cuestionario consta de cuatro preguntas cerradas con cinco posibles respuestas, a saber: A) muy en desacuerdo; B) en desacuerdo; C) ni de acuerdo ni en desacuerdo; D) de acuerdo; E) muy de acuerdo o totalmente de acuerdo. A ello se une una quinta pregunta abierta para que el alumno pueda realizar sugerencias que, tras el correspondiente análisis, puedan aplicarse dentro de su proceso de formación, lógicamente a partir del siguiente curso académico: 1 . ¿Cree usted que el tiem-

Téngase en cuenta que este trabajo se realizó antes de la reforma del art. 68 de la Ley Orgánica de Universidades, operada por el Real Decreto-ley 14/2012, de 20 de abril, de medidas urgentes de racionalización del gasto público en el ámbito educativo: «No obstante, la dedicación a la actividad docente de este personal podrá variar en función de la actividad investigadora reconocida de conformidad con el Real Decreto 1086/1989, de 28 de agosto, sobre retribuciones del profesorado universitario, y que haya dado lugar a la percepción del complemento de productividad previsto en el art. 2.4 del mismo y atendiendo a las siguientes reglas:

a) Deberá dedicar a la función docente la parte de la jornada necesaria para impartir en cada curso un total de dieciséis créditos ECTS quien se encuentre en alguna de las siguientes situaciones:

- Profesores titulares de universidad, profesores titulares de escuelas universitarias o catedráticos de escuela universitaria con tres o más evaluaciones positivas consecutivas, habiéndose superado la más reciente en los últimos seis años.

- Catedráticos de universidad con cuatro o más evaluaciones positivas consecutivas, habiéndose superado la más reciente en los últimos seis años.

- En todo caso, cuando se hayan superado favorablemente cinco evaluaciones.

b) Deberá dedicar a la función docente la parte de la jornada necesaria para impartir en cada curso un total de treinta y dos créditos ECTS quien se encuentre en alguna de las siguientes situaciones:

- Que no haya sometido a evaluación el primer periodo de seis años de actividad investigadora o que haya obtenido una evaluación negativa de dicho periodo.

- Que hayan transcurrido más de seis años desde la última evaluación positiva».

Foro, Nueva época, vol. 15, núm. 2 (2012): 309-336 
po que destinan las diferentes asignaturas de su grado es el suficiente para su preparación en la adquisición de competencias esenciales para el ejercicio profesional? 2. ¿Considera adecuado el proceso de evaluación continua para medir los conocimientos adquiridos en grado? 3. ¿Considera que la autoevaluación contribuye o puede contribuir a fomentar su capacidad de reflexión y de aprendizaje autónomo? 4. Un ejercicio de reflexión: ¿se considera suficientemente capacitado para utilizar la autoevaluación como técnica de aprendizaje? 5. Una pregunta abierta (responda en el reverso): desde su trayectoria como estudiante universitario de grado, ¿cómo evaluaría usted o qué otras fórmulas de evaluación utilizaría para medir los diferentes tipos de conocimientos adquiridos para su desempeño profesional?

En palabras de las autoras, estas cuestiones se centran en diversos aspectos fundamentales del grado ${ }^{41}$ :

- Un plan de estudios reflejado en el porcentaje de tiempo que destinan las diferentes asignaturas a la preparación del estudiante para su vida profesional.

- La evaluación continua que promueve el nuevo plan.

- La viabilidad de una técnica que incentiva la autonomía en el aprendizaje, como es la autoevaluación, y que sirve de símbolo y representación de las nuevas metodologías didácticas que promueve el Espacio Europeo de Educación Superior.

- La capacidad del estudiante para profundizar en su autoconocimiento de una forma reflexiva e incentivar su compromiso en el aprendizaje.

- La posibilidad para el estudiante de expresar con libertad su opinión a estos y a otros posibles asuntos en una última pregunta abierta en la que tendrían cabida de una manera explícita tanto críticas como reconocimientos y posibles sugerencias.

\section{RESULTADOS DE LA ENCUESTA}

Conforme a lo señalado en el apartado segundo de este trabajo, los resultados de las encuestas son los siguientes:

${ }^{41}$ Cfr. A. Rodríguez Rivas y C. Cosculluela Martínez, «Los estudiantes demandan más carga docente en asignaturas clave para su formación profesional», op. cit., p. 29. 


\section{TABLA 1}

Distribución del número de alumnos que responden a cada una de las preguntas formuladas con formato cerrado

\begin{tabular}{|l|c|c|c|c|c|}
\hline Grupo & Alumnos & $\begin{array}{c}\text { Pregunta 1 } \\
\text { numero de } \\
\text { respuestas } \\
A-B-C-D-E\end{array}$ & $\begin{array}{c}\text { Pregunta 2 } \\
\text { numero de } \\
\text { respuestas } \\
A-B-C-D-E\end{array}$ & $\begin{array}{c}\text { Pregunta 3 } \\
\text { numero de } \\
\text { respuestas } \\
A-B-C-D-E\end{array}$ & $\begin{array}{c}\text { Pregunta 4 } \\
\text { numero de } \\
\text { respuestas } \\
A-B-C-D-E\end{array}$ \\
\hline 1. $^{\circ}$ A (grado) & 13 & $0-3-6-3-1$ & $1-1-2-9-0$ & $1-3-3-5-1$ & $2-1-1-8-1$ \\
\hline 1. $^{\circ}$ E (grado) & 18 & $3-6-6-3-0$ & $4-1-3-9-1$ & $2-5-1-7-3$ & $3-4-3-6-2$ \\
\hline $3 .^{\circ}$ E (licenciatura) & 8 & $0-0-1-6-1$ & $0-0-1-5-2$ & $2-1-2-3-0$ & $2-0-2-4-0$ \\
\hline
\end{tabular}

TABLA 2

Porcentajes que representan los resultados obtenidos en la tabla anterior

\begin{tabular}{|c|c|c|c|c|c|}
\hline Grupo & Alumnos & $\begin{array}{l}\text { Pregunta } 1 \\
\text { porcentaje } \\
\text { de respuestas }\end{array}$ & $\begin{array}{l}\text { Pregunta } 2 \\
\text { porcentaje } \\
\text { de respuestas }\end{array}$ & $\begin{array}{l}\text { Pregunta } 3 \\
\text { Porcentaje } \\
\text { de respuestas }\end{array}$ & $\begin{array}{c}\text { Pregunta } 4 \\
\text { porcentaje } \\
\text { de respuestas }\end{array}$ \\
\hline 1. ${ }^{\circ} \mathrm{A}$ (grado) & 13 & $\begin{array}{l}\text { A - } 0 \\
\text { B - } 23,07 \\
\text { C - } 46,15 \\
\text { D - } 23,07 \\
\text { E - } 6,66\end{array}$ & $\begin{array}{l}\text { A - 7,69 } \\
\text { B - 7,69 } \\
\text { C - } 15,38 \\
\text { D - 69,23 } \\
\text { E - } 0\end{array}$ & $\begin{array}{l}\text { A - } 7,69 \\
\text { B - } 23,07 \\
\text { C - } 23,07 \\
\text { D - } 38,46 \\
\text { E - } 7,69\end{array}$ & $\begin{array}{l}\text { A - 15,38 } \\
\text { B - 7,69 } \\
\text { C - 7,69 } \\
\text { D - 61,54 } \\
\text { E - 7,69 }\end{array}$ \\
\hline 1. ${ }^{\circ} \mathrm{E}$ (grado) & 18 & $\begin{array}{l}\text { A - } 16,66 \\
\text { B }-33,33 \\
C-33,33 \\
D-16,66 \\
\text { E- } 0\end{array}$ & $\begin{array}{l}\text { A - 22,22 } \\
\text { B - 5,55 } \\
C-16,66 \\
D-50,00 \\
\text { E- } 5,55\end{array}$ & $\begin{array}{l}\text { A - } 11,11 \\
\text { B - } 27,77 \\
\text { C - } 5,55 \\
\text { D - 38,88 } \\
\text { E - } 16,66\end{array}$ & $\begin{array}{l}\text { A - } 16,66 \\
\text { B - } 22,22 \\
\text { C - } 16,66 \\
D-33,33 \\
\text { E- } 11,11\end{array}$ \\
\hline 3. ${ }^{\circ} \mathrm{E}$ (licenciatura) & 8 & $\begin{array}{l}\text { A - } 0 \\
\text { B - 0 } \\
\text { C - } 12,50 \\
\text { D - } 75,00 \\
\text { E - } 12,50\end{array}$ & $\begin{array}{l}\text { A - } 0 \\
\text { B - } 0 \\
\text { C - } 12,50 \\
\text { D - } 62,50 \\
\text { E - } 25,00\end{array}$ & $\begin{array}{l}\text { A - } 25,00 \\
\text { B - } 12,50 \\
\text { C - } 25,00 \\
\text { D - } 37,50 \\
\text { E - } 0\end{array}$ & $\begin{array}{l}\text { A - } 25,00 \\
\text { B - } 0 \\
\text { C - } 25,00 \\
\text { D - } 50,00 \\
\text { E - } 0\end{array}$ \\
\hline
\end{tabular}

\section{TABLA 3}

Conformidad de los alumnos con el cuestionario planteado: supuestos en los cuales la suma de las respuestas d y e (muy de acuerdo y de acuerdo) superan a la suma de las respuesta a y $b$ (en desacuerdo y muy en desacuerdo)

\begin{tabular}{|l|c|c|c|c|c|}
\hline Grupo & Alumnos & $\begin{array}{c}\text { Pregunta 1 } \\
\text { porcentaje de } \\
\text { respuestas }\end{array}$ & $\begin{array}{c}\text { Pregunta 2 } \\
\text { porcentaje de } \\
\text { respuestas }\end{array}$ & $\begin{array}{c}\text { Pregunta 3 } \\
\text { porcentaje } \\
\text { de respuestas }\end{array}$ & $\begin{array}{c}\text { Pregunta 4 } \\
\text { porcentaje } \\
\text { de respuestas }\end{array}$ \\
\hline $1 .^{\circ} \mathrm{A}$ (grado) & 13 & no & sí & sí & sí \\
\hline $1 .^{\circ} \mathrm{E}$ (grado) & 18 & no & sí & sí & sí \\
\hline $3 .^{\circ} \mathrm{E}$ (licenciatura) & 8 & no & sí & igual & sí \\
\hline
\end{tabular}

Foro, Nueva época, vol. 15, núm. 2 (2012): 309-336 
La primera consideración en cuanto a los resultados necesariamente ha de ser positiva. En prácticamente todas las cuestiones formuladas a los alumnos de grado, el número de estudiantes que responden a las opciones «D» $\mathrm{y} \ll \mathrm{E} »$ (de acuerdo y muy de acuerdo o totalmente de acuerdo) es superior al conjunto de las respuestas $\langle\mathrm{A} » \mathrm{y}\langle\mathrm{B} \gg$ (muy en desacuerdo y en desacuerdo). Únicamente se planteó una mayoría de respuestas desfavorables en la primera de las preguntas: ¿Cree usted que el tiempo que destinan las diferentes asignaturas de su grado es el suficiente para su preparación en la adquisición de competencias esenciales para el ejercicio profesional? Discrepancia ésta a la que ha de unirse, en esa misma pregunta, un considerable número de alumnos que responden «C» (ni de acuerdo ni en desacuerdo).

Los alumnos de tercer curso de licenciatura, que como ya he indicado cursaron la asignatura en idénticas condiciones a sus compañeros de grado, se decantaron a responder aún con mayor conformidad a las cuestiones primera y segunda, situándose algo más reacios que sus compañeros del nuevo plan de estudios en las preguntas tercera y cuarta. Ello probablemente tiene su explicación en la singularidad del supuesto, ya que la aplicación novedosa de la autoevaluación como técnica de aprendizaje en alumnos que ya se encuentran habituados a otros sistemas genera dudas razonables en los mismos, de tal forma que, pese a ser alumnos de mayor edad que los de grado a los que se ha encuestado en este trabajo, y con un mayor bagaje personal (al cursar tercer año de estudios universitarios), se muestran ligeramente más reacios en este aspecto.

Otro elemento a tener en cuenta es la seguridad del alumno de grado en sus propias capacidades, como se expresa de forma patente en la pregunta 4 (un ejercicio de reflexión: ¿se considera suficientemente capacitado para utilizar la autoevaluación como técnica de aprendizaje?), pero que también subyace en la número 3 (¿considera que la autoevaluación contribuye o puede contribuir a fomentar su capacidad de reflexión y de aprendizaje autónomo?). En relación con estas respuestas, ante la duda de si tal confianza personal se encuentra directamente relacionada con la aplicación del propio plan de estudios o si se trata de un rasgo propio generacional, probablemente se debe a la suma de ambos. Aunque indudablemente, el hecho de encontrarse inmersos en un sistema que tiene en ese elemento uno de sus rasgos distintivos no es algo baladí, pudiendo deducirse que han interiorizado este extremo de Bolonia.

Igualmente, otro dato de notable interés es el que se pone de manifiesto por la discrepancia entre lo verbalmente manifestado por los discentes y 
lo consignado en las encuestas, ya que la evaluación continua se propugna por ellos, de forma muy mayoritaria, como medio plenamente válido para realizar dicha evaluación. Dicha evaluación continua presupone, evidentemente, un trabajo que habrá de ser ininterrumpido desde el comienzo del curso, ya que muy difícilmente puede realizarse evaluación alguna en ausencia de aquél. Ahora bien, por lo que luego se comentará, los alumnos indicaron, de forma mayoritaria, la complejidad que les suponía su realización continua en las diferentes materias.

En cuanto a la última pregunta, formulada de manera deliberadamente abierta, fue contestada por una mayoría de alumnos. Las cuestiones que plantean pueden centrarse en dos bloques:

1. Prácticas: los encuestados demandan la realización de un mayor número de prácticas ${ }^{42}$, lo cual parece entrar en contradicción con lo expresado por ellos verbalmente, al señalar la sobrecarga de trabajo que les supone la llevanza del curso. En ciertos casos matizan aún más, señalando que deben realizarse sobre casos reales, visitarse centros de trabajo (juzgados, notarías, despachos de abogados), contándose también con la visita puntual de profesionales ajenos al centro para que realicen alguna práctica. No falta quien señala que ha de reducirse el peso de los exámenes (o incluso suprimirse). Puntualmente se señala que la evaluación sería más acertada si se dedicaran más horas en clase para la elaboración de casos y se incrementara el nivel de esfuerzo del alumnado.

Opción esta última que puede resultar de interés, al conciliar las demandas de los discentes con una vía razonable para su ejercicio. No se trataría, pues, de eliminar necesariamente las prácticas a realizar fuera de clase, sino de combinar unas y otras en función de las circunstancias de la asignatura (nivel de dificultad, adecuación de la explicación a los plazos consignados en la Guía de grado, concentración de exámenes, etc).

${ }^{42}$ Esta cuestión no resulta cuestión baladí, toda vez que en el estudio realizado por Rodríguez Rivas y Cosculluela Martínez se señala expresamente que: «Un alto porcentaje de los encuestados también lamenta la exigencia de la realización constante de trabajos a los que no ven utilidad ni encuentran adecuación a la vida laboral» (A. RodRíguez Rivas y C. CoscullueLA MARTínEZ, «Los estudiantes demandan más carga docente en asignaturas clave para su formación profesional», op. cit., p. 29). Ahora bien, entiendo que ha de tenerse sumo cuidado al manejar esa cuestión. Pensando — por ejemplo- en primer curso de Derecho, conformado por treinta semanas de clases, si se realiza un sistema Bolonia stricto sensu, con una práctica por semana y asignatura, nos encontramos con que el año finalizaría con 270 prácticas, complementadas con los correspondientes exámenes, algo verdaderamente irrazonable para docentes y alumnos. Así pues, para moderar estas cifras no es infrecuente que durante el primer mes en el que se imparte cada asignatura no se realicen prácticas, para poder ver un porcentaje mínimamente significativo del temario que permita así realizar aquéllas de forma razonable. 
Y no falta quien manifiesta que los exámenes deberían ser orales (para acostumbrar al alumno al futuro ejercicio profesional) ${ }^{43}$ y tener un contenido eminentemente práctico. Esta última vía deviene especialmente interesante, toda vez que en las asignaturas de Derecho ello es perfectamente posible. No obstante, la realización de un examen práctico, teniendo los alumnos a su disposición códigos y leyes, requiere un fuerte nivel de preparación de la asignatura, que probablemente excedería de las treinta horas previstas para superar cada ECTS ${ }^{44}$. Los alumnos de licenciatura responden de manera semejante, demandando más prácticas ${ }^{45}$.

2. Críticas al «Sistema Bolonia»: los alumnos señalan que el tiempo dedicado a cada asignatura en los planes de estudio es insuficiente para profundizar en las diversas materias, hasta el punto que una parte considerable de los encuestados aboga sin tapujos por el retorno a la licenciatura. En cuanto a este punto, considero que habría que deslindar dos aspectos:

El primero de ellos, que una parte importante del alumnado aún no ha interiorizado buena parte de la filosofía de los nuevos planes de estudios, pretendiendo volcar el protagonismo en el docente y no en ellos mismos, lo que acaso pueda justificarse por el tipo de enseñanza media recibida. Gran parte del esfuerzo ha de realizarse, necesariamente, fuera del aula. De hecho, ésa es la piedra angular sobre la que se asienta el ECTS. Pretender impartir Bolonia centrando la carga del proceso de aprendizaje en el docente resultaría tan erróneo como inviable, sobremanera si se tiene en cuenta el considerable número de materias a impartir en cuatro años. Por ello, acaso sería deseable que al comienzo de cada grado se impartieran una serie de charlas sobre el funcionamiento de Bolonia. Y que incluso dichas charlas se organizaran en institutos de bachillerato con docentes universitarios.

${ }^{43}$ Tanto en grado como en licenciatura, durante el curso 2011-2012 se dio la opción de realizar los exámenes de ambas formas a los alumnos encuestados, optando por el oral en torno al 10 por 100. El 90 por 100 restante decidió acudir al examen escrito, con un formato tradicional.

${ }^{44} \mathrm{Mi}$ experiencia personal en cuanto a los exámenes concebidos para subir nota, en los cuales los alumnos pueden acudir sin límite de códigos o manuales, muestra que normalmente no alcanzan dicha progresión en la calificación.

${ }^{45}$ Otro problema de entidad se plantea con las prácticas en el caso de los alumnos que suspenden la asignatura teniendo las prácticas igualmente suspensas. Se plantea aquí la posibilidad de recuperar el examen en la siguiente convocatoria pero, paradójicamente, la imposibilidad de recuperar las prácticas. Hecho éste cuestionable, ya que el alumno, antes de realizar el examen de septiembre, tiene ya su nota condicionada en el porcentaje designado por la guía (normalmente el 30 o 40 por 100), por lo que ante unas prácticas incorrectas el estudiante se ve obligado a obtener al menos un notable (o en muchos casos, un sobresaliente) en el examen para superar la asignatura con un aprobado. Así pues, el concepto clásico de convocatoria queda igualmente alterado. 
El segundo tiene que ver con el propio diseño del plan de estudios. Un rápido vistazo al mismo (en este caso, grado en Derecho UCM de 2009) permite comprobar que las asignaturas son prácticamente coincidentes con las del Plan 1953, aunque parcialmente aligeradas de contenidos. Cambio que no ha estado exento de polémica ${ }^{46}$. Otro tanto ocurre con los contenidos, que se asimilan en gran medida. Así pues, en tres años (pues el último está destinado a elegir el correspondiente itinerario de Derecho público o privado) el alumno ha de asimilar la práctica totalidad del contenido de los antiguos cinco cursos de la licenciatura, con la complejidad añadida de realizar prácticas de manera continuada.

Evidentemente, en tales resultados no se contemplan más apartados que los ya comentados, pero no cabe duda que la actitud del docente - pese a todas estas dificultades - también se pondera en las respuestas, aun de forma tácita. La interacción se hace presente nuevamente, pudiendo ser la vía auxiliar conseguir una mejor valoración del sistema, sea cual fuere el sistema empleado, paliándose así las posibles deficiencias del mismo. Evidentemente, eso exige un profundo compromiso del docente. Así, el modelo de la denominada «Ventana Johari» ${ }^{47}$ :

- Los factores subjetivos dictan nuestras impresiones sobre los demás.

- Las emociones influyen en la conducta más que la razón o la lógica.

- Los seres humanos tienen una consciencia limitada de su yo y se benefician de la información procedente de otras fuentes.

- El cambio promueve la posibilidad de aprender y desarrollarse.

- La experiencia es fluida y siempre cambiante.

${ }^{46}$ En este sentido, debe traerse a colación el manifiesto «Saquemos los estudios de Derecho del proceso de Bolonia», del cual forman parte un considerable número de los juristas con mayor auctoritas en España: «El proceso de reforma de los planes universitarios conocido como proceso de Bolonia puede suponer para los estudios de Derecho en nuestro país un paso atrás, seguramente irreversible, que determinará la degradación de las profesiones jurídicas y el empequeñecimiento de la aportación de los juristas a la organización de la convivencia y la estructuración de la sociedad española del siglo xxi. El daño que tal retroceso ocasionará a la construcción de las instituciones y la articulación de las relaciones entre ciudadanos y poderes públicos no puede ser pasado por alto. Nos sentimos por ello en el deber de hacer una seria advertencia a la comunidad universitaria y a la autoridad educativa, y solicitar con toda firmeza que los estudios jurídicos sean excluidos del proceso de Bolonia y tratados con el rigor que su importancia requiere» (cfr. www.lapaginadefinitiva. com/aboix/?p=206).

47 Por todos, vid. A. BRockbank y I. McGill, Aprendizaje reflexivo en la educación superior, op. cit., p. 195.

Foro, Nueva época, vol. 15, núm. 2 (2012): 309-336 


\section{CONCLUSIONES}

Se pone de manifiesto que incluso en centros de reducidas dimensiones, a priori ideales para implantar el nuevo sistema, éste no se encuentra exento de problemas e incluso de ciertas resistencias en el alumnado para su aplicación. Si a tal coyuntura se une la problemática derivada de un exceso de alumnos, se genera un contexto altamente complejo para el docente.

Efectivamente, para la correcta aplicación de «Bolonia» es totalmente imprescindible la urgente racionalización del número de alumnos por clase, ya que es incompatible aplicar de forma generalizada en toda España un nuevo sistema sobre la base actual, diseñada para otro tipo de planes. Más aún, ése debía haber sido uno de los presupuestos básicos para implantar la transformación en los planes de estudios. Contemplando la cuestión desde otro prisma, habría sido necesario realizar, con carácter previo, una evaluación rigurosa de los recursos humanos idóneos para el adecuado funcionamiento del grado, conforme a sus necesidades presentes y futuras ${ }^{48}$.

A mi juicio, no dándose las condiciones necesarias, debería haberse postergado su puesta en funcionamiento hasta —al menos - verificarse la reducción efectiva del número de alumnos. Probablemente, en este punto se confió demasiado en cuestiones tan aleatorias como un eventual descenso demográfico ${ }^{49} \mathrm{o}$ la propia dinámica del mercado laboral ${ }^{50}$ que apuntaban a la disminución de aquéllos. Pero incluso habiéndose producido el ya indicado «Bolonia coste cero» habría continuando siendo verdadera contradictio in terminis.

Ahora, generado ya el problema, ha de arbitrarse la solución. Teóricamente y a priori se plantean diversas formas. La primera, implementan-

${ }^{48} \mathrm{Cfr}$. A. Block, Innovación educativa. El sistema integral de enseñanza-aprendizaje, México, Trillas, 1974. Organigrama IX disponible en el anexo sin paginar.

49 «En España, el previsible descenso de la presión demográfica en los próximos años comportará, sin duda, una excelente oportunidad para un mejor aprovechamiento de los recursos humanos y materiales, a la vez que resultará parcialmente compensada por el incremento de la demanda de todas las capas sociales de acceso a la educación superior y a la necesidad de atender a las exigencias de una formación continuada a lo largo de la vida» («La integracion del sistema universitario español en el espacio europeo de enseñanza superior», documento-marco, Ministerio de Educación, Cultura y Deporte, 2003, p. 5, disponible en www.queesbolonia.gob.es/dctm/queesbolonia/documentos/declaraciondebolonia.pdf?documentId=0901e72b8004c356).

${ }_{50} \mathrm{O}$ acaso en la posibilidad de encontrar por aquellos tiempos, con relativa facilidad, trabajos bien remunerados que no requerían cualificación universitaria. 
do una gran inversión no sólo en personal, sino también en medios materiales. Muchas facultades están especialmente configuradas para atender grupos con un elevado número de alumnos y cualquier reforma que pretendiera realizarse en ese orden (caso de poder realizarse) resultaría muy compleja. Y en el ámbito del personal, estamos en un indiscutible proceso de amortización de plazas que, aun de forma más tímida, se inició hace probablemente un lustro. Valga como muestra que las plazas de «ayudante» dejaron de convocarse en la UCM en los últimos años, sacrificándose así los objetivos de formación e investigación de las nuevas generaciones (vitales en muchas facultades, con una elevada edad media del profesorado y un incierto relevo del personal a corto y medio plazo) por las inaplazables necesidades docentes del servicio ${ }^{51}$. Ante la difícil coyuntura económica, transformar esa estructura resulta inviable ${ }^{52}$.

Otra posible forma de alcanzar los objetivos impuestos por Bolonia sería reduciendo paulatinamente el número de alumnos que acceden a la universidad, elevando así la nota de corte, con lo que se posibilitaría una adecuada interacción entre docentes y estudiantes, así como que estos últimos accedieran al grado teniendo un mejor bagaje que les permitiera enfrentarse desde un adecuado punto de partida a la educación superior. Esta opción (que parece estar llevándose a cabo en determinados centros $)^{53}$ podría combinarse con la elevación de las tasas académicas para alumnos repetidores, lo que podría disuadir a los discentes de matricularse de un número excesivo de asignaturas ${ }^{54}$. En este sentido, resulta alta-

51 Especialmente rigurosas entre 2010 y 2014 en la Facultad de Derecho UCM por la coexistencia del grado y la licenciatura.

52 No obstante, no puede olvidarse que la LOU impone una serie de porcentajes sobre las diferentes figuras de docentes con vínculo funcionarial, laboral o administrativo. En los departamentos de las universidades públicas los profesores funcionarios (desde 2001 necesariamente doctores acreditados) han de ser superiores en número a los del resto de categorías juntas. Ello, que resulta plenamente razonable, deviene obstáculo extraordinariamente complejo para las personas que inician su carrera al suprimirse de facto los primeros escalones de la carrera docente. La persona que consigue el título de doctor se ve obligada en muchas ocasiones a buscar otros destinos, ya que, en el mejor de los casos, necesitará varios años de duro trabajo para conseguir la correspondiente acreditación en el ámbito laboral.

53 Así, la Facultad de Derecho UCM, que en los últimos quince años ha restringido prácticamente a la mitad el número de alumnos admitidos en el primer curso de Derecho.

${ }^{54}$ Así debe destacarse la modalidad de «matrícula a tiempo parcial» de la UCM, en la cual «los estudiantes podrán cursar sus estudios bajo la modalidad de tiempo parcial, matriculando en un curso académico menos créditos de los establecidos en el apartado anterior referido a tiempo completo. Los estudiantes matriculados en esta modalidad deberán matricular en todo caso un mínimo de treinta créditos en el curso académico, salvo que les resten menos créditos para finalizar sus estudios o que la titulación, por sus características específicas, establezca, en su caso, una cifra menor» (Acuerdo del Consejo de Gobierno de fecha 14 
mente cuestionable que, invariablemente, con independencia de la asignatura que pueda tomarse como referencia, un porcentaje de alumnos - que en no pocas ocasiones resulta significativo- no consuman ninguna convocatoria de examen, no acudan nunca a clase y eludan realizar cualesquiera de las actividades propuestas, careciendo en gran medida de justificación objetiva tales comportamientos.

Todo ello sin descartar una tercera vía, uniendo las anteriores. Reducir en parte el número de alumnos y moderar los objetivos de Bolonia. No en vano, probablemente éstos devinieron demasiado ambiciosos ${ }^{55}$, sobre todo teniendo en cuenta que, en muchos casos, los estudiantes que acceden a la universidad no alcanzan las destrezas que teóricamente les presupone la Ley, habiendo de trabajar sobre ellas ${ }^{56}$. Y acaso ha llegado el momento de plantearse la reforma. Sin perjuicio del número de asignaturas, recuérdese el número de competencias ${ }^{57}$ del grado en Derecho, nada menos que 48 distribuidas en 10 transversales, 12 genéricas y 26 específicas, superándose en gran medida los mínimos previstos en el Real Decreto 1393/2007, de 29 de octubre, por el que se establece la ordenación de las enseñanzas universitarias oficiales ${ }^{58}$. Recuérdese que por competencia se

de octubre de 2008 en el que se aprueba la normativa de permanencia del estudiantado en la Universidad Complutense de Madrid, BOUC, núm. 14, 20 de noviembre de 2008).

55 «Los grados de 240 créditos facilitarán el acceso al entorno laboral, al ser un título universitario fácilmente reconocible sin la necesidad de un segundo nivel de formación» (cfr. www.queesbolonia.gob.es/queesbolonia/preguntas-con-respuesta/por-que-los-grados-en-espnaduran-cuatro-anos-en-vez-tres. $b$ tml).

${ }^{56}$ Más complejos resultan los casos en los que los estudios universitarios parten de un nivel de conocimientos de, por ejemplo, matemáticas que no se cumplen en la práctica.

57 Una competencia recoge un modo de proceder característico que se considera adecuado ante una situación planteada en el ejercicio profesional. Ese modo característico de proceder, que identifica al profesional que lo posee como competente, no está referido a su conocimiento de un tema específico o a su dominio de una técnica concreta. Lo que determina su competencia es la demostración de que posee una capacidad para comprender las situaciones, evaluar su significado y decidir cómo debe afrontarlas. Su competencia implica una combinación compleja de conocimientos, técnicas, habilidades y valores que resulta crítica para hacer bien aquello que se le exige en las circunstancias en las que se encuentre mientras realiza una actividad profesional. Por todos, vid. M. DE Miguel DíAz, Adaptación de los planes de estudio al proceso de convergencia europea, Dirección General de Universidades, Programa de estudios y análisis, Proyecto EA 2004-0024, octubre de 2004, disponible en www. ub.edu/eees/documents/pdfes/mec/mec_2004.pdf.

${ }_{58}$ Así, el art. 3.2 del Anexo I: «Se garantizarán, como mínimo, las siguientes competencias básicas en el caso del grado y aquellas otras que figuren en el Marco Español de Cualificaciones para la Educación Superior (MECES): que los estudiantes hayan demostrado poseer y comprender conocimientos en un área de estudio que parte de la base de la educación secundaria general, y se suele encontrar a un nivel que, si bien se apoya en libros de texto avanzados, incluye también algunos aspectos que implican conocimientos proceden- 
entiende la aptitud o capacidad de movilizar rápida y pertinentemente toda una serie de recursos, conocimientos, habilidades y actitudes para afrontar de manera eficiente determinadas situaciones ${ }^{59}$, aunque en el ámbito doctrinal el vocablo destreza resultaría el más equivalente ${ }^{60}$. De ahí que un número nada despreciable de las mismas sea —a mi juicio- propia de estudios de postgrado, como la CT6, Capacidad para la negociación, conciliación y toma de decisiones ${ }^{61}$, y la CT10, Desarrollo de habilidades de iniciación a la investigación. Los resultados de las encuestas realizadas apoyan esta tesis, como pone de manifiesto la mayoría de respuestas negativas a la cuestión: ¿Cree usted que el tiempo que destinan las diferentes asignaturas de su grado es el suficiente para su preparación en la adquisición de competencias esenciales para el ejercicio profesional?

Evidentemente, el alumno de primer curso - como regla general- no se encuentra habituado a las exigencias propias del ámbito universitario. La inmensa mayoría accede al grado directamente de la enseñanza media y cuenta con poca o nula experiencia laboral, lo que condiciona la percepción personal de cada cual, pero, a mi juicio, la escasez de tiempo en el aula resulta incuestionable.

Aún así, en un contexto con tantas dificultades, el papel del profesor, tan denostado socialmente, alcanza una importancia mayúscula, al poder invertir parcialmente esta situación a través de la motivación al alumnado. Ahora bien, motivar sin estar motivado, más que un juego de palabras es una realidad en muchos casos. Tan importante como la motivación

tes de la vanguardia de su campo de estudio; que los estudiantes sepan aplicar sus conocimientos a su trabajo o vocación de una forma profesional y posean las competencias que suelen demostrarse por medio de la elaboración y defensa de argumentos y la resolución de problemas dentro de su área de estudio; que los estudiantes tengan la capacidad de reunir e interpretar datos relevantes (normalmente dentro de su área de estudio) para emitir juicios que incluyan una reflexión sobre temas relevantes de índole social, científica o ética; que los estudiantes puedan transmitir información, ideas, problemas y soluciones a un público tanto especializado como no especializado; que los estudiantes hayan desarrollado aquellas habilidades de aprendizaje necesarias para emprender estudios posteriores con un alto grado de autonomía».

59 Cfr. www.educacion.gob.es/boloniaensecundaria/glosario-c.btm.

${ }^{60}$ Por todos, vid. S. Meseguer Velasco, «Competencias genéricas y específicas: precisión de conceptos», en J. Rodríguez-Arana Muñoz y R. Palomino Lozano (dirs.), Enseñar Derecho en el Siglo XXI. Una guía práctica sobre el Grado en Derecho, op. cit., p. 89.

${ }^{61}$ En su defecto, para lograr tales destrezas lo más razonable sería su impartición en el marco de una asignatura $a d$ boc, la cual hasta la fecha no se encuentra en el plan de estudios del grado en Derecho de la UCM. Cfr. S. Meseguer VelasCo, «Negociación y mediación», en J. Rodríguez-Arana Muñoz y R. Palomino Lozano (dirs.), Enseñar Derecho en el Siglo XXI. Una guía práctica sobre el Grado en Derecho, op. cit., pp. 249 y ss. 
del alumno es la del docente. Sin embargo, la implantación de Bolonia ha coincido, desafortunadamente, con una drástica reducción y posterior congelación de salarios en las universidades públicas, incluyendo la desaparición de facto de determinados complementos salariales ${ }^{62}$. Uno de los presupuestos del sistema integral de enseñanza-aprendizaje que a mi juicio constituye Bolonia quiebra por completo ${ }^{63}$.

Pero no por ello hay que eludir la adopción de medidas realistas que refuercen la motivación del profesorado y sean admisibles en el contexto actual. Así, la simplificación y reducción de las tareas administrativas que consumen gran parte del tiempo que habría de dedicarse al estudio e investigación. Caso paradigmático es el volcado del curriculum del docente en múltiples plataformas, completamente independientes unas de otras.

Y una última conclusión de este estudio es el carácter crítico con respecto al sistema del alumno medio de grado, que en la pregunta abierta del cuestionario respondió de forma mucho más contundente que sus compañeros de la licenciatura. Acaso ésta pudiera ser una consecuencia positiva de la introducción de Bolonia.

${ }^{62}$ Así, el caso del complemento autonómico por méritos individuales del personal docente e investigador de las universidades públicas de la Comunidad de Madrid, que mientras se escriben estas líneas (julio de 2012) aún carece de la publicación de la correspondiente Orden.

${ }^{63}$ «Mantener al personal existente en condiciones óptimas en cuanto a su desarrollo, satisfacción y relaciones humanas» (A. BLOCK, Innovación educativa. El sistema integral de enseñanza-aprendizaje, op. cit., organigrama IX disponible en el anexo sin paginar). 